Buana Sains Vol 18 No 2: 125 - 130, 2018

\title{
ANALISA RESIDU PESTISIDA DI WILAYAH MALANG DAN PENANGGULANGANYA UNTUK KEAMANAN PANGAN BUAH JERUK
}

\author{
Astri Sumiati dan Reza Prakoso Dwi Julianto \\ Program Studi Agroteknologi, Fakultas Pertanian, Universitas Tribhuwana Tunggadewi
}

\begin{abstract}
The use of pesticides is widely used in the production of citrus fruits for protection before and after harvest. The use of pesticides on a broad scale can pollute the environment and leave residues in plants and in plants such as fruit leaves and tubers. A survey was conducted to evaluate the level of pesticide residues in citrus fruits. The survey method is carried out by recording pesticide use by farmers and traders. The survey will be conducted in Dau, Batu and Poncokusumo Districts, Malang Regency by interviewing 10 farmers and 10 orange traders in each District.

The Gas Cromatography method was carried out to measure the levels of pesticide residues tested at the Angler Biochemlab Laboratory, Surabaya. Descriptive analysis was used to analyze the levels of pesticide residues in citrus fruits then compared to the Maximum Residue Limit (BMR) through SNI 7313: 2008 quality standards on agricultural products.

The residue levels of profenofos in farmer samples were found to be higher at $0.108 \mathrm{ppm}$ compared to the sample from traders, namely $0.050 \mathrm{ppm}$ at the Tegalweru village research site. In addition, traders in the village of Poncokusumo knew the imidaclroripid content was close to the maximum threshold of $0.040 \mathrm{ppm}$ in farmer samples and $0.010 \mathrm{ppm}$ in the merchant sample. Decreased levels of pesticide residues on food can be done with several approaches, namely physically and chemically. Reduction of pesticide residues in agricultural products can be done in several ways including by washing products with running water for several times or can also be done by soaking in water for one hour
\end{abstract}

Keywords: Pesticide residues; citrus fruits; surveys; Malang; gas cromatography.

\section{Pendahuluan}

Di seluruh dunia, petani menggunakan pestisida untuk perlindungan terhadap kehilangan panen akibat hama dan penyakit. Jumlah pestisida dan tingkat penggunaannya dalam pertanian telah meningkat pesat selama beberapa tahun terakhir. Ketergantungan petani Indonesia terhadap pestisida dapat dilihat dari peningkatan penggunaan pestisida pada tahun 1998 dari 11.587,2ton menjadi 17.977,2ton pada tahun 2000. Aplikasi pestisida yang paling banyak dilakukan adalah pada tanaman hortikultura terutama tanaman sayuran (Hasibuan, 2015). Pestisida kimia seringkali digunakan oleh Petani Indonesia $(95,29 \%)$ sebagai sarana pengendalian Organisme Pengganggu Tanaman (OPT) 
karena efektif, efisien dan dianggap menguntungkan secara ekonomi. (Balingtan, 2013).

Aplikasi pestisida di pertanian dan perkebunan dimulai dari awal hingga akhir siklus penanaman yang terdiri dari pengolahan tanah, penyiapan lahan tanam, pemeliharaan tanaman, pemanenan hingga pascapanen. Penggunaan pestisida yang tidak tepat dapat meningkatkan resiko pada pangan, lingkungan, dan kesehatan. Paparan pestisida telah dikaitkan dengan spektrum bahaya kesehatan manusia yang luas, mulai dari dampak jangka pendek seperti sakit kepala dan mual hingga penyakit kronis seperti kanker dan gangguan endokrin.

Pestisida organophosphate dan karbamat juga menyebabkan efek buruk pada sistem saraf pusat dan penghambatan enzim asetil cholinesterase (Chen et al., 2011). Pada penelitian yang menguji 315 sampel dari produk pertanian ditemukan adanya kandungan residu pestisida sebanyak $47 \%$ pada sampel produk segar dan $7 \%$ terdapat kandungan residu pestida pada sampel makanan olahan. Pada tahun 1998, dilakukan pengujian residu pestisida pada 180 sampel sayuran, dari total keseluruhan sampel sayuran yang diuji, 89\% merupakan produk segar sedangkan $11 \%$ merupakan produk olahan. Dari hasil pengujian terhadap residu pestisida, ditemukan 35\% sampel produk segar yang mengandung residu pestisida dan $10 \%$ dari sampel sayuran olahan yang mengandung residu pestisida (Ahmed dkk, 2011). Penelitian tersebut telah menunjukkan bahwa tanaman yang diaplikasi dengan pestisida masih banyak tertinggal residu pestisida. Untuk menanggulangi bahaya pestisida pada kesehatan manusia dan lingkungan diperlukan Analisa mengenai kandungan residu pestisida pada buah jeruk sehingga dapat dilakukan pencegahan dan pengendalian agar residu pestisida yang terbawa tidak menimbulkan kerugian pada kesehatan manusia dan lingkungan.

\section{Metode Penelitian}

Metode penelitian berupa survey yang dilakukan terhadap beberapa petani dan pedagang jeruk yang ada di wilayah Batu dan Kabupaten Malang. Pada penelitian ini diambil 2 lokasi utama pertanaman jeruk yaitu di desa Poncokusumo dan desa Tegalweru. Penelitian dilakukan dengan mewawancarai 10 petani dan 10 pedagang jeruk. Pada proses pertama jeruk akan dibeli sebanyak $10 \mathrm{~kg}$ dari masing-masing petani demikian pula untuk setiap pedagang juga akan dibeli sebanyak $10 \mathrm{~kg}$ (sekitar 60 buah jeruk manis). Selanjutnya Buah jeruk yang telah dikumpulkan dari setiap petani dan pedagang akan diambil masing-masing sebanyak $5 \mathrm{~kg}$ untuk selanjutnya dilakukan Analisa kadar residu pestisidanya di PT. Angler Biochemlab Surabaya.

Pengukuran kada residu pestisida dilakukan dengan menggunakan metode gas Chromatografi untuk 2 sampel buah jeruk yang didapatkan dari petani dan pedagang jeruk. Data kadar residu pestisida pada buah jeruk nantinya dibandingkan dengan baku mutu SNI 7313: 2008 tentang Batas Maksimum Residu pada hasil pertanian. Selanjutnya dibuat pembahasan dan analisa kadar residu pestisida dalam buah jeruk.

\section{Hasil dan Pembahasan}

\section{Kadar Residu Pestisida dalam Buah Jeruk}

Analisa kadar Residu Pestisida dalam buah jeruk yang menggunakan beragam jenis pestisida akan meninggalkan residu pada buah jeruk yang dihasilkan, seperti: 
A. Sumiati dan R. P. D. Julianto/ Buana Sains Vol 18 No 2 : 125-130

Tabel 1. Residu Pestisida Organophosphat dan Karbamat dalam Buah Jeruk

\begin{tabular}{|c|c|c|c|c|c|}
\hline \multirow[t]{2}{*}{$\begin{array}{l}\text { Residu } \\
\text { Pestisida }\end{array}$} & \multicolumn{2}{|c|}{$\begin{array}{l}\text { Kecamatan Dau, } \\
\text { Kota Batu, Malang }\end{array}$} & \multicolumn{2}{|c|}{$\begin{array}{l}\text { Kecamatan Poncokusumo, } \\
\text { Kabupaten Malang }\end{array}$} & \multirow{2}{*}{$\begin{array}{c}\text { LOD } \\
\text { Ppm } \\
(\mathrm{mg} / \mathrm{kg})\end{array}$} \\
\hline & $\begin{array}{l}\text { Sampel } \\
\text { Petani } \\
\text { Ppm } \\
(\mathrm{mg} / \mathrm{kg})\end{array}$ & $\begin{array}{l}\text { Sampel } \\
\text { Pedagang } \\
\text { Ppm } \\
(\mathrm{mg} / \mathrm{kg})\end{array}$ & $\begin{array}{l}\text { Sampel } \\
\text { Petani } \\
\text { Ppm } \\
(\mathrm{mg} / \mathrm{kg})\end{array}$ & $\begin{array}{l}\text { Sampel } \\
\text { Pedagang } \\
\text { Ppm } \\
(\mathrm{mg} / \mathrm{kg})\end{array}$ & \\
\hline Acephate & $<0,005$ & $<0,005$ & 0.010 & 0.010 & 5 \\
\hline Carbofuran & $<0,005$ & $<0,005$ & 0.010 & 0.010 & 0,1 \\
\hline Carbosulfan & $<0,005$ & $<0,005$ & 0.010 & 0.010 & 2 \\
\hline Diazinon & $<0,005$ & $<0,005$ & 0.010 & 0.010 & 0,7 \\
\hline Dimethomorp & $<0,005$ & $<0,005$ & 0.010 & 0.010 & 2 \\
\hline Fenobucarb & $<0,005$ & $<0,005$ & 0.010 & 0.010 & 0,5 \\
\hline Profenofos & 0,108 & 0,050 & 0.010 & 0.010 & 1 \\
\hline Imidacloprid & $<0,005$ & $<0,005$ & 0.040 & 0.010 & 0,05 \\
\hline
\end{tabular}

Sumber: data primer

Residu pestisida ditemukan di dalam buah jeruk yang dihasilkan oleh petani, hal ini berkaitan dengan jenis pestisida yang digunakan yaitu insektisida dan fungisida sistemik. Cara kerja dari insektisida sistemik yaitu diserap oleh bagian-bagian tanaman melalui stomata, meristem akar, lentisel batang dan celah-celah alami. Selanjutnya insektisida akan melewati sel-sel menuju ke jaringan pengangkut baik xylem maupun floem. insektisida nantinya akan meninggalkan residunya pada bagian sel-sel yang telah dilewatinya. Melalui pembuluh angkut nantinya insektisida ditranslokasikan ke bagian-bagian tanaman lain. Cara kerja dari insektisida ini adalah mematikan serangga yang memakan bagian tanaman yang mengandung residu insektisida. Adapun jenis insektisida yang paling toksik diantara pestisida lainnya dan sering menyebabkan keracunan yaitu jenis Organophosphat.

Bila termakan, meskipun dalam jumlah sedikit saja, dapat menyebabkan kematian. Sebagian besar bahan aktif golongan organofosfat sudah dilarang beredar di Indonesia, misalnya diazinon, fention, fenitroteion, fentoat, klorpirifos, kuinalfos, dan malation, sedangkan bahan aktif lainnya masih diijinkan. Bahan aktif dari golongan ini cukup banyak digunakan pada beberapa jenis pestisida.

Dari hasil pengujian di laboratorium diketahui untuk kadar residu pestisida pada kelompok organophosphat (profenofos) semuanya masih di bawah Limit of Detection (LOD), artinya kadar residu pestisida yang diukur tidak terbaca oleh alat. Hal ini mengandung dua kemungkinan, yaitu pada buah jeruk tidak ditemukan residu pestisida kelompok organophosphat atau kemungkinan ada residu tetapi di bawah nilai LOD dari alat pengujian.

Hasil ini kemungkinan juga disebabkan oleh penggunaan formulasi pestida oleh petani jeruk yang mencampur beberapa jenis pestisida sehingga mengakibatkan tidak terdeteksinya residu pestisida pada alat kromatografi gas karena alat tersebut tidak mampu mendeteksi be- 
A. Sumiati dan R. P. D. Julianto/ Buana Sains Vol 18 No 2 : 125-130

berapa formulasi pesisida yang dicampur. Penurunan kadar residu pestisida pada pangan dapat dilakukan dengan beberapa pendekatan yaitu secara fisik dan kimia, seperti pada produk pertanian residu pestisida dapat diturunkan dengan mencuci produk tersebut dengan air yang mengalir untuk beberapa kali, kemudian direndam di dalam air selama satu jam. Selain itu, beberapa hasil penelitian melaporkan bahwa detergen dapat digunakan untuk melepaskan residu pestisida pada buahbuahan (Indraningsih, 2008). Tetapi untuk buah jeruk hal ini perlu dibuktikan terlebih dahulu karena buah jeruk mempunyai kulit dan biasa dikunsumsi dengan cara segar.

Adapun penghilangan kadar residu pestisida yang terdapat pada hasil pertanian tergantung pada berbagai faktor, seperti, langkah pengolahan dari awal tanam sampai panen dan sifat kimia pestisida itu sendiri (Chavarri dkk., 2005). Perlakuan pengolahan saat melakukan penanaman juga sering berpengaruh terhadap kadar residu pestisida, akan tetapi hal itu tidak selalu berhubungan dengan sifat fisika-kimia pestisida itu sendiri (Bonnechère dkk., 2012). Salah satu cara yang dapat dilakukan untuk menurunkan residu pestisida pada buah dan tanaman adalah dengan mengatur jarak/frekuensi penyemprotan pestisida sesuai dengan golongannya karena masa degradasi organophosphat dan karbamat dalam lingkungan sekitar 2 minggu, maka frekuensi/jarak penyemprotan golongan ini adalah 2 minggu sekali.

\section{Kesimpulan}

Simpulan hasil penelitian pada petani jeruk di Desa Tegalweru Kota Batu dan Desa Poncokusumo Kabupaten Malang adalah, 1) Petani dalam menggunakan pestisida tidak sesuai dengan petunjuk yang tertera pada kemasan, 2) Buah jeruk hasil panen petani mengandung residu profenofos (Organophospat) dengan kadar 0,050- 0,108 ppm.
Selain itu pada sample pedagang di poncokusumo diketahu kandungan imidaclroripid yang mendekati ambang batas maksimum yaitu $0,040 \mathrm{ppm}$ untuk petani dan $0,010 \mathrm{ppm}$

\section{Daftar Pustaka}

Ahmed, A., Randhawa, M. A., Yusuf, M. J., Khalid, N. (2011) Effect of processing on pesticide residues in food crops - A Review, Journal of Agricultural Research, 49, 379 - 390.

Balingtan (2013) Teknologi menurunkan residu pestisida di lahan pertanian, http:/ / balingtan.litbang.pertanian.go.id / ind/index.php/berita/138teknologimenurunkan-residu-pestisidadi-lahanpertanian, diakses tanggal 6 Agustus 2016.

Badrudin, U., dan Jazilah, S. (2013) Analisis residu pestisida pada tanaman bawang merah (Allium ascalonicum L.) di Kabupaten Brebes, Jurnal Ilmu Pengetahuan dan Teknologi, 24 (1), 75 $-86$.

Bonnechère, A., Hanot, V., Jolie, R., Hendrickx, M., Bragard, C., Bedoret, T., Loco, J. V. (2012) Processing factors of several pesticides and degradation products in carrots by household and industrial processing, Journal of Food Research, 1 (3), $68-83$.

Chavarri, M. J., Herrera, A., Arino, A. (2005) The decrease in pesticides in fruit and vegetables during commercial processsing, International Journal of Food Science and Technology, 40, 205 $-211$

Chen, C., Qian, Y., Chen, Q., Tao, C., Li, C., \& Li, Y. (2011). Evaluation of pesticide residues in fruits and vegetables from Xiamen, China. Food Control, 22(7), 
A. Sumiati dan R. P. D. Julianto/ Buana Sains Vol 18 No 2 : 125-130

1114-1120.http://dx.doi.org/10.1016/j. foodcont.2011.01.007.

Fernandez M, Pico Y, Man es J. 2001. Pesticide residues in oranges from Valencia (Spain). Food Additives and Contaminants 18:615-624.

Hasibuan R. 2015. Insektisida Organik Sintetik dan Biorasional. Bandar Lampung: Plantaxia. hlm. 8-72.

Indraningsih. 2008. Pengaruh Penggunaan Insektisida Karbamat terhadap Kesehatan Ternak dan Produknya. Wartazoa Vol. 18 No. 2 Tahun 2008: 101-114.

Miskiyah dan Munarso, S. J. (2009) Kontaminasi residu pestisida pada cabai merah, selada, dan bawang merah (Studi Kasus di Bandungan dan Brebes Jawa Tengah serta Cianjur Jawa Barat), J. Hort., 19(1), 101 - 111.

Satpathy, G., Tyagi, Y. K., Gupta, R. K., (2012) Removal of organophosphorus (OP) pesticide residues from vegetables using washing solutions and boiling, Journal of Agricultural Science, 4(2), 69 -78 . 
